\section{Обоснование размеров области напряжений в почве под действием механической нагрузки}

\author{
А. М. Цыпук ${ }^{1}$
}

Петрозаводский государственный университет

В статье приведены результаты теоретических исследований распространения напряжений в почве. Область напряжений имеет форму конуса трения, основание которого находится там, где напряжение $\sigma$, являющееся следствием нагрузки, выравнивается по величине с сопротивлением почвы смятию [ $\sigma]$, Па. Получены аналитичєские выражения для расчета дальности распространения напряжения в однородной среде.

Ключевые слова: почва, напряжение, сопротивление смятию, угол трения, деформатор, зона рьхления.

При решении многих теоретических задач, связанньг с обработкой почвы, возникает необходимость определения дальности распространения наптяжения под действием механической нагрузки. Из теории обработки почвы известно, что напряжения в ней распространяются перпендикулярно к поверхности деформатора, а на границах его - под углом внутреннего трения к нормальным векторам. Например, при обработке почвы культиватором, область напряжений перед рабочим органом типа долота называется зоной рыхления. Установлено, что ширина этой зоны значительно превышает ширину долота и в ней происходит подвижка частиц почвы [1].

Величина напряжения убывает по мере удаления от деформатора.

Если вектор силы, создающей напряжение в почве при обработке, направлен к ее поверхности изнутри, происходит вспучивание почвы, что наблюдается визуально. В этом случае дальность распространения области нагтяжений естественно ограничена поверхностью почвы. Если вектор силы направлен в глубь почвы, дальность распространения области напряжений можно оценить экспериментально: тензометрированием или по деформации слоев почвы, искусственно созданных контрастным материалом (меловым порошком).

Экспериментальные исследования не дают ответа на вопрос об истинной дальности распространения напряжений в почве, т. к. всегда можно предположить, что при большей чувствительности приборов слабые напряжения можно зарегистрировать на пюбом расстоянии от деформатора. Отсюда возникает

\footnotetext{
${ }^{1}$ Автор - профессор кафедры технологии и оборудования лесного комплекса

() А. М. Цыпук, 1999
}

необходимость теоретического обоснования этого вопроса.

Рассмотрим простейшую схему образования области напряжений под воздействием на поверхность почвы силы $\mathbf{N}$ через деформатор, площадь которого мала (рис. 1).

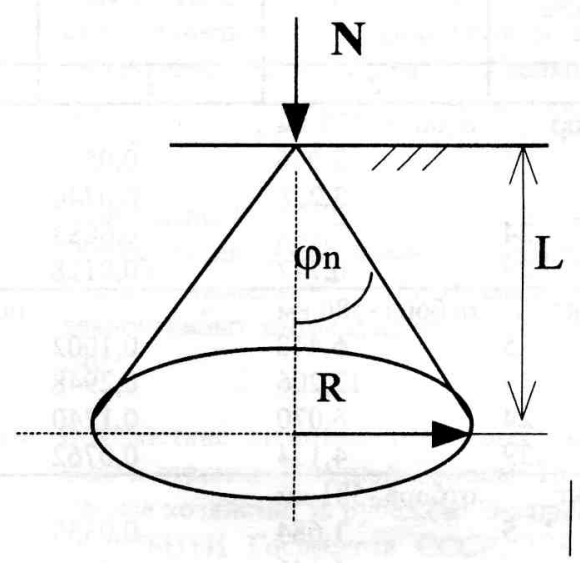

Рис. 1. Область напряжений в почве от точечного деформатора

Найдем величину напряжения $\sigma$ в плоскости, отстоящей на некоторое расстояние $\mathbf{L}$ от поверхности почвы. Радиус $\mathbf{R}$ основания конуса определится из выражения

$\mathrm{R}=\mathrm{L} \operatorname{tg} \varphi_{\mathrm{n}}=\mathrm{L} \mathrm{f}_{\mathrm{n}}$,

где $\varphi_{\mathbf{n}}$ - угол внутреннего трения; $\mathbf{f}_{\mathbf{n}}$ - коэффициент трения в среде почва-почва (являются объективными механическими характеристиками почвы).

Площадь $\mathbf{S}$ основания определится из выражения

$\mathrm{S}=\pi \mathrm{L}^{2} \mathrm{f}_{\mathrm{n}}^{2}$

Величина $\sigma$ напряжения определится по известной формуле

$\sigma=\mathrm{N} / \mathrm{S}$

Нагряжение будет убывать пропорционально квадрату расстояния от поверхности почвы.

На основе анализа изученньг явлений в различньх областях физики можно предположить, что на некотором удалении величина $\sigma$ сравняется с удельным сопротивлением почвы смятию [ $\sigma]$, после чего дальнейшее распространение области напряжений, вы- 
званньх действием силы $\mathbf{N}$, прекратится. Позволим провести аналогию с взаимодействием полей (магнитных, электрических), граница которого приходится на поверхность, где напряженности уравновешиваются. Заметим, что принятые посылки не противоречат диалектическому принципу единства мира.

На основании вышеизложенного, максимальная дальность распространения напряжений $\mathbf{L}_{1}$ от точечного деформатора определится из выражения

$\mathrm{L}_{1}=\sqrt{\frac{\mathrm{N}}{\sigma \sigma] \pi \mathrm{f}_{\mathrm{n}}^{2}}}$.

На рис. 2 представлена схема воздействия на поверхность почвы силой $\mathbf{N}$ через деформатор в виде круга радиусом $\mathbf{r}$.

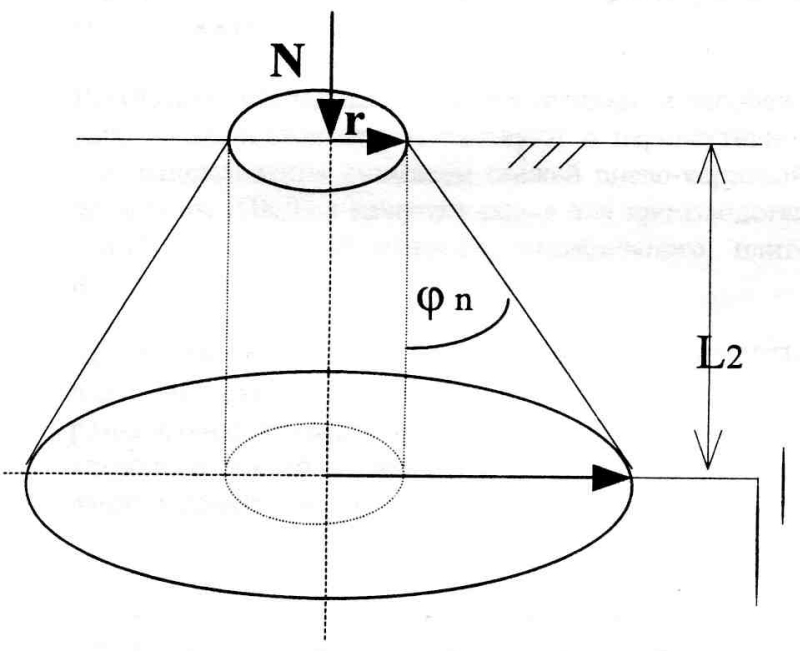

Рис. 2. Область нагряжений в почве от круглого деформатора

Максимальная дальность $\mathbf{L}_{2}$ распространения напряжений от круглого плоского деформатора определится из выражения

$\mathrm{L}_{2}=-\mathrm{A}+\sqrt{\mathrm{A}^{2}+\mathrm{B}}$

где величины А и В имеют значения

$$
A=r / f_{n}, B=\left(N /[\sigma] \pi-r^{2}\right) / f_{n}^{2}
$$

Рассмотрим численные примеры. В качестве механических характеристик почвы примем величины, замеренные при полевьх исследованиях подрезки корней сеянщев в лесном питомнике [2]: [ $\sigma]=108$ кПа; $\mathbf{f}_{\mathbf{n}}=$ 0,37 .

Пример 1. $\mathrm{N}=10 \mathrm{\kappa H}, \mathbf{r}=0,1 \mathrm{м}$.

Величина $\mathbf{L}_{2}$ получается 0,19 м.

Пример 2. $\mathrm{N}=10 \mathrm{\kappa H}, \mathbf{r}=0,2 \mathrm{м}$.

Расчетная величина $\mathbf{L}_{2}$ получается $-0,08$ м, т. е. отрицательная, что на первый взгляд ставит под сомнение корректность предлагаемой методики.

Определим по формуле (3), какое напряжение $\sigma$ создается непосредственно под деформатором, на границе его контакта с почвой, и получим величину $79,6 \mathrm{k \Pi а,} \mathrm{т.} \mathrm{е.} \sigma<[\sigma]$ !

На практике это будет означать, что действие усилия $\mathbf{N}$ на почву не проявится, в частности, не останется даже отпечатка деформатора.

Решение задачи для деформатора, например квадратной формы со стороной а (рис. 3), также будет иметь вид (5), но значения $\mathbf{A}$ и $\mathbf{B}$ будут иными:

$$
A=2 a / \pi f_{n}, B=\left(N /[\sigma]-a^{2}\right) / \pi f_{n}^{2}
$$

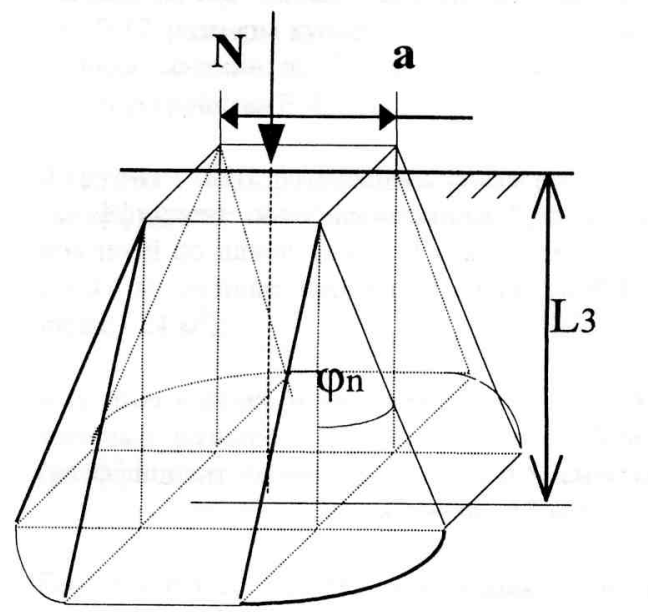

Рис. 3. Область напряжений в почве от квадратного деформатора

Экспериментальная проверка предложенной методики расчета была выполнена для обоснования рабочей скорости корнеподрезчика [3], при этом расхождение с расчетными данными не превысило $5 \%$, т. е. сходимость результатов вполне удовлетворительная.

По предварительным данным, предложенную методику обоснования размеров области напряжений в 
почве под действием механической нагрузки можно также успешно применить для решения задач уплотнения грунта в строительстве и многих других.

Материалы статьи были доложены автором и одобрены на теоретическом семинаре кафедры механики строительного факультета Петрозаводского госуниверситета 6 марта 1997 года.

\section{ЛИТЕРАТУРА}

1. Зима И. М., Малюгин Т. Т. Механизация лесохозяйственньхх работ. М.: Лесная пром-сть, 1976. $416 \mathrm{c}$.
2. Цыпук А. М. Повышение эффективности лесовосстановительньх работ ресурсосберегающей технологией: Автореф. дис. ... д-ра техн. наук / ЛТА. СПб., 1996. 299 с.

3. Цыпук А. М. Обоснование скорости резания корнеподрезчика для лесньх питомников // Повышение качества машин и механизмов в процессе проектирования, изготовления, эксплуатации и ремонта: Межвуз. сб. науч. тр. / ЛТА. СПб., 1996. С.156-160. 